\title{
Secure Online Electronic Civil Registration Using Cloud Computing: A Conceptual Framework \\ OJO OLANREWAJU.
}

Computer Technology Department

Yaba College of Technology, Lagos Nigeria

${ }^{2}$ AKINADE ABIGAIL OLUWATOYIN

Computer Technology Department

Yaba College of Technology, Lagos Nigeria

${ }^{3}$ TOKUNBO-COLE MARY O.

Computer Engineering Department

Yaba College of Technology, Lagos Nigeria

-ABSTRACT-

Population counting and distribution is vital to planning and resources allocation of the nation. The birth and death registration is a good starting point for population counting and archive. Accurate record of birth and death is vital to population estimate of a country. In this modern day of ICT and computer proliferation it is sadden that Nigeria and other African countries are still registering birth and death manually hence excluded from benefit accrue to proper birth and death registration. This work proposed real-time online birth and death registration system for Nigerian citizen. The choice of programming language shall be PHP (Hypertext preprocessor) for server-side scripting while action script and Macromedia-Flash for media content authoring and MySQL shall be used as the back-end database.

Index Terms: Birth Registration, Death Registration, Civil Registration, Cloud Computing, Electronic Civil Registration

Date of Submission: Apr 25, 2020

Date of Acceptance: May 08, 2020

\section{INTRODUCTION}

Countries need to know how many people are born and die each year, and the main causes of their deaths in order to have well-functioning health systems. The only way to count everyone and to track all births and deaths is through Civil Registration. The United Nations defines civil registration as "the continuous, permanent, compulsory and universal recording of the occurrence and characteristics of vital events pertaining to the population as provided through decree or regulation in accordance with the legal requirements of a country [1].

Online communication and computer Networking is becoming sin-qua-non in day today activities due to the way people are been connected through the use of computer system and other online devices and technology which easily allow embedded and better security of data and information compare to manual processing of doing things [2]

Civil registration provides the basis for individual legal identity but also allows countries to identify their most pressing health issues.Civil registration systems are the most reliable source of statistics on births and deaths, and causes of death. Countries that do not have a wellfunctioning civil registration system only have approximate ideas of the numbers, the longevity and the health of their population [3].

Civil registration brings multiple benefits. An individual's right to be counted at both extremes of life is fundamental to social inclusion. In the absence of insurance or inheritance, death registration and certification are often required prerequisites for burial, remarriage, or the resolution of criminal cases [4].

A recent Plan study estimates that 51 million babies are not registered at birth. Without a birth certificate, children may lack access to services like health care and education. Globally, two-thirds (38 million) of 56 million annual deaths are still not registered and every year, almost half of the world's children go unregistered. This could have adverse effect to citizenry and hamper the country development. Africa has largest percentage of unregistered birth and death. Globally, two-thirds (38 million) of 56 million annual deaths are still not registered and cause of death not known. Hence governments cannot design effective public health policies or measure their impact. More than half of the Nigeria children go unregistered after birth. Due to the current birth registration system which is $100 \%$ manual and prone to several errors and fraud related to birth registration [5].

Many barriers prevent people from registering births and deaths. Many countries do not have the necessary laws, infrastructures, to make it obligatory to register births and deaths. In some countries, only people who live in cities have access to registration services. A simple birth certificate which is final product of birth registration we take for granted in Nigeria can change a child's life. Here's how: [6]

- It opens up a world of health care. Every year, millions of children die from preventable diseases before they reach the age of five. Unregistered 
children are often unable to gain access to health care services or pay more for those services than a registered child. But a birth certificate means a child can access medical treatment and the vaccinations he or she needs to stay healthy.

- It means an education. Without birth registration, a child can be kept from participating at school. But with a birth certificate, a child will have the necessary documentation needed to enroll in publicly funded schools.

- It can provide protection. Without identification, government officials have no documentation of a child's existence. As a result, the law is incapable of protecting children from crimes and abuse. But effective birth registration protects children and provides them with their legal rights.

- It can help provide an inheritance. If an unregistered child's parents pass away, they need to legally prove they are related to inherit their family property. But with birth registration, a child will have the legal proof of their family ties, ensuring they receive what belongs to them.

- It creates a permanent record of existence. If a disaster strikes and a child is separated from his or her family, a reunion could be next to impossible without proper identification. But with birth registration, government officials can safely unite families and prevent any child from going unaccounted for.

- A child with no birth registration may be prone to:Lack of recognition and support which will ultimately make life more difficult for children as they grow older.

The main focus of this work is to develop a Web-Based Application System for Universal Civil Registration in Nigeria: A Case Study, So that Nigeria can join some

\section{REVIEW OF RELATED WORKS}

\section{A. Existing Birth Registration In Nigeria}

The existing birthregistration system in Nigeria is manual. Hence prone to double registration which in turn could results to all form of criminal activities such as falsification of age, ghost workers especially in civil service which aftermath effect could affect our economy negatively. For example in the civil service, employee change their age in other to remain in service for as long as they want and this has resulted to adverse effect on employment opportunity for younger ones, Several political office holders in the past have been challenged of their true age declaration [7].

Death registration benefit, when deaths go uncounted and the causes of death are not documented; governments cannot design effective public health policies or measure their impact.

This research work if successfully completed it will provide an infrastructure platform required for civil registration with particular reference to death and birth registration that will produce a Unique, Secure Birth and
Death Certificate for every birth and death registration in Nigeria. Also eliminate barriers to birth registration in our dear country, and it will eliminate some problems associated with unregistered birth and death in our country either to the individual or country at large [8].

The researchers shall embark on campaign tours for Universal Birth and Death Registration campaign in the rural areas forselected local government areas of federal republic of Nigeria during which the prototype of the system will be test run, for at least five (5) millions birth registrations [9].

\section{B. Benefit of Birth Registration}

Birth registration and birth certificates contribute to an individual's sense of citizenship and, overall, to the coherence of civil society.At the national level, every country needs to know its own vital statistics - its characteristics and trends in terms of births, deaths and other key indicators, such as marriage, divorce and fertility. In simple terms, every government needs to know how many people there are in the country, and how it can plan to meet their needs. Civil registration is, for example, the most accurate way to update population census data collected at ten-year intervals. Effective registration that provides detailed information on population growth at every administrative level, from national to local, allows a government to measure not only overall trends in fertility and mortality, but also differentials among population groups and administrative levels. It allows the analysis of fertility and mortality rates by age, and the development of projections of demographic change. It helps to identify geographic, social and gender disparities within the national boundaries - the least developed parts of a country may have the lowest birth registration coverage and the greatest need for services and active support. Without accurate population data, these areas may be overlooked and denied the necessary budgetary resources. The lack of such data may, therefore, lead to the further exclusion of people already marginalized from the social and economic life of their country.The data provided by effective civil registration allow the accurate planning, development and implementation of development policies, particularly in health, education, housing, water and sanitation, employment and agricultural and industrial production. They enhance a country's ability to monitor and evaluate the impact of these policies and help governments allocate appropriate resources to those in greatest need, thereby narrowing disparities. In addition, data provided by registration are invaluable to the lifecycle approach to human development.They can be used to plan and coordinate immunization efforts, monitor child growth, promote universal enrolment in primary education, monitor and address drop out - particularly among girls - and other key steps in a child's life.From a health perspective, continuous information on births and deaths is essential for the compilation of crucial development indicators such as statistics on perinatal, neonatal, infant, child and general mortality at all administrative levels. Civil registration goes beyond development issues to contribute to improved governance 
and is an important element in a well-rooted democracy. Electoral rolls are compiled from a country's civil register and could reduce or eliminate all hardship and cost incurred on voter registration, and the credibility and transparency of voting lists, the prevention of electoral fraud and the possibility for all citizens to enjoy their democratic rights are, therefore, dependent on accurate data on births and deaths $[10.11,12]$.

\section{Why International Organisation/Agencies Are Interested In Civil Registration}

International Organisation/Agencies Are Interested in Civil Registration because of it is immense contribution to the developmental plan of the nation and management of crises and disaster. Health agencies like WHO, civil registration systems are the most reliable source of statistics on births and deaths, and causes of death. Countries that do not have a well-functioning civil registration system only have approximate ideas of the numbers, the longevity and the health of their population [13].

Civil registration brings multiple benefits. An individual's right to be counted at both extremes of life is fundamental to social inclusion. In the absence of insurance or inheritance, death registration and certification are often required prerequisites for burial, remarriage, or the resolution of criminal cases [14].

\section{Role of the United Nation IN Civil Registration}

There is no single agency within the United Nations responsible for helping countries set up and manage civil registration. However, the United Nations Statistics Division (UNSD), the United Nations Children's Fund (UNICEF), the United Nations Population Fund (UNFPA) and the United Nations Development Programme (UNDP) all work with developing countries to improve different aspects of their population statistics. WHO, and its partner the Health Metrics Network, focus on improving health information systems and the ability of countries to track major causes of death [15].

A global meeting on the strengthening of civil registration and vital statistics systems (CRVS) held in December 2013 noted the role of the health sector in strengthening CRVS, and identified principles and practices which contribute to broader CRVS strengthening. The meeting recognised the momentum globally to improve CRVS and the means through which health sectors can contribute to this strengthening [16].

\section{E. Barriers To Civil Registration (Birth and Death registration)}

Many barriers prevent people from registering births and deaths. Many countries do not have the necessary laws or infrastructure to make it obligatory to register births and deaths. In some countries, only people who live in cities have access to registration services [17]. This includes;

- Infrastructure barriers

- Political barriers

- Legislative barriers

- Administrative barriers

- Economic barriers

- Neglect of cultural and community realities

- Geographic barriers

- Gender discrimination

- War and internal conflict

\section{RESEARCH METHODOLOGY}

\section{A. Data Collection}

Data was collected from sampled population of 85 buildings in Sango-Ota Ogun State to know the status of birth registration of various occupants of the buildings. The range of inhabitants of the building vary from 5 to 12 . Majority of the sample population has no evidence of birth registration. Out of 675 sample population only 105 has birth certificate which show evidence of birth registration.

\section{B. Proposed Design And Implementation}

We proposed PHP (Hypertext pre-processor) for server-side scripting and Actionscript and MicormediaFlash for media content authoring and Mysql as the backend database. There will be user's interaction through GUI by following particular order of interaction. As part of security measure every user that will perform action on the system must first of all registered and approved by the system administrator. There will be authorization limits for every users. The user's categories and roles that can be performed by them are explicitly highlighted in the proposed design flowchart shown in figure 1 . 


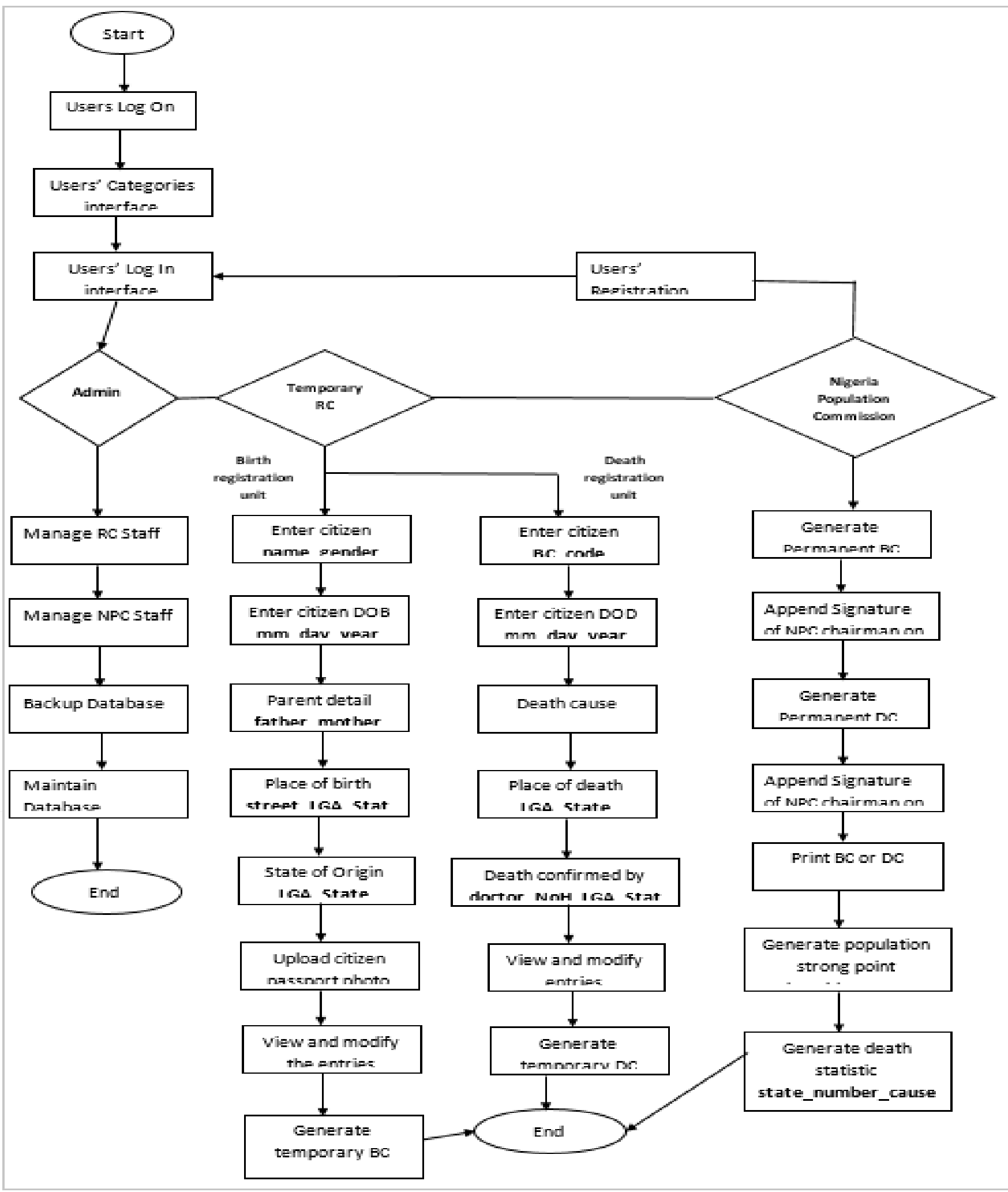

Figure 1. Flowchart of proposed Online Electronic Civil Registration System 


\section{CONCLUSION}

The existing birth registration system in Nigeria is manual. Hence prone to double registration which in turn could results to all form of criminal activities such as falsification of age, ghost workers especiallye in civil service which aftermath effect could affect our economy negatively.Implementation of this conceptual framework could bring about the following benefit among others: reduce cost of birth and death registration process to the citizenry and Nigeria government; reduce the number of personnel's and administration involved in the birth registration' registration processes through replacement of existing manual modes of birth registration in Nigeria with the aid of automated system; promote easy updating of civil registered within a particular time frame so that such register can be used for other national assignment e.g electoral roll, policy formulation, distribution of resources etc; prevent multiple birth registration, and false age declaration which is rampart in Nigeria currently; produce a reliable civil registration system that will provide vital statistics needed for demographic management and future development plan in Nigeria. Etc.

\section{REFERENCES}

[1] Yekini N. A., Aigbokhan E. E, and Okikiola F. M.Int. J. Advanced Networking and Applications Volume: 6 Issue: 1 Pages: 2151-2157 (2014) ISSN: 0975-0290

[2] Akoto, Eliwo (2010), 'Recording of Births in SubSaharanAfrica: What Strategies Can be Adopted to Improve on

[3] Annan, Kofi A. (2001), We the Children: End-Decade Review of the Follow-Up to the World Summit for Children: Report of the United Nations SecretaryGeneral, UNICEF, New York.

[4] Concluding Observations of the Committee on the Rights of the Child: Saudi Arabia. 26/01/2001. CRC/C/15/Add.148 (para 23).

[5] Dow, Unity (1998), 'Birth Registration: the "First" Right', in UNICEF, The Progress of Nations 1998, UNICEF, New York.

[6] Farooq, G. and E.M. Pernia (2014), 'Need for and Approaches to Integrated Population, Human Resource and Development Planning', Population Bulletin of the United Nations, no. 23-24.

[7] Haj Adnan, H. (1998), Campaign for Unregistered Children in SUMOUD Camp. Badil Resource Center, Bethlehem.

[8] Herber, Mark D.; Society of Genealogists (Great Britain) (March 1998). Ancestral trails: the complete guide to British genealogy and family history. Genealogical Pub. Co., Inc. p. 36. ISBN 978-0-80631541-6. Retrieved 30 June 2011.

[9] Lalicon, Carlito B. (2000), 'Registration of Births in the Philippines', paper presented at the National Workshop on Birth Registration (sponsored by
PLAN-InternationalPakistan), Islamabad, Pakistan, May 16-17, 2000.

[10]Planning birth Registration: http://planinternational.org/about-plan/consultancy-research-todetermine-the-benefits-of-birth-registration.

[11]Public Record, Registry of Births, Deaths and Marriages - Queensland

[12] UN Committee on the Rights of the Child (1997), Concluding Observations of the Committee on the Rights of the Child: Syrian Arab Republic. 24/01/1997. CRC/C/15/Add.70.

[13] UN Committee on the Rights of the Child (2001), ConcludingObservations of the Committee on the Rights of the Child:Kyrgyzstan, 09/08/2000, CRC/C/15/Add.127, and UN.

[14] UNHCHR (2015). Promotion and Protection of the Rights of Children: Sale of Children, Child Prostitution and Child Pornography, Report by the Special Rapporteur of theCommission on Human Rights.

[15] UNICEF (2009), Progress since the World Summit for Children, 'Levels of Birth Registration, UNICEF, New York.

[16] United Nations Department of Economic and Social Affairs, Statistics Division, (2016), Handbook on Civil Registration andVital Statistics Systems. Preparation of Legal Framework, United Nations, New York.

[17] United Nations Department of Economic and Social Affairs, Statistics Division (2001), Handbook on Civil Registration and Vital StatisticsSystems. Management, Operation and Maintenance, United Nations, New York. 